\title{
Application of TODIM (TOmada de Decisao Interativa Multicriterio) method for under- construction housing project selection in Kolkata
}

\author{
Shankar Chakraborty ${ }^{*}$ and Abkishek Chakraborty
}

Department of Production Engineering, Jadavpur University, Kolkata, India

\begin{tabular}{l}
\hline C H R O N I C L E \\
\hline Article history: \\
Received: November 5, 2017 \\
Received in revised format: Feb- \\
ruary 20, 2017 \\
Accepted: March 22, 2018 \\
Available online: \\
March 22, 2018 \\
\hline Keywords: \\
Under-construction \\
Housing project \\
TODIM method \\
Risk \\
Rank
\end{tabular}

\section{A B S T R A C T}

\begin{abstract}
The paper focuses on the application of TODIM (TOmada de Decisao Interativa Multicriterio), which means in Portuguese 'interactive and multi-criteria decision making') method in identifying the most attractive and affordable under-construction housing project in the city of Kolkata in India. In this decision making problem, 14 under-construction housing projects spanning in and around Kolkata are evaluated with respect to ten important criteria. The deployment of TODIM method can well be validated with respect to its ability to deal with both qualitative and quantitative criteria in the presence of risk factors. This method is also acknowledged to be a robust tool being almost unaffected by the varying values of the attenuation factor of losses. Using TODIM method, an under-construction housing project at Rajarhat in the eastern fringes of Kolkata city is selected as the optimal choice while meeting the requirements of investors, inhabitants and other stakeholders.
\end{abstract}

\section{Introduction}

Kolkata, the 'city of palaces' and 'city of joy', is the state capital of West Bengal and former capital (1772-1911) of British India. Situated on the western banks of the Hooghly River, it forms the eastern fringes of West Bengal, and is close to the Bay of Bengal and the neighbouring country, Bangladesh. It is also one of the four metropolitan cities of India. Due to its positional advantages, this city has been developed as a point of transshipment from water to land and from river to sea, facilitating growth in commerce, transport and manufacture. Kolkata enjoys a rich cultural heritage, and is often treated as the cultural and educational hub of India. The popularity of Kolkata reached its peak during the preindependence period and gradually, the city has developed as an important commercial centre. Its civic administration is bestowed in the hands of different administrative bodies of the state government. Some of its demographical features which are worth to mention here are area : $1480 \mathrm{sq} \mathrm{km}(205 \mathrm{sq} \mathrm{km}$ is within Corporation Area); pollution (as on 2011) : 4,496,694; population density: 24,760/sq km; population ratio : male - 1000, female - 956 ; literacy rate : $81.31 \%$; and mother tongues : Bengali 55\%,

\footnotetext{
* Corresponding author.

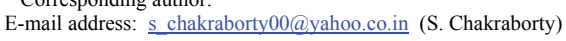


Hindi $20 \%$, English $10 \%$ and others $15 \%$. It is the seventh largest city of India both in area and population.

Although, the city of Kolkata has a stretch of over 8-10 km on the western banks of the Hooghly River, reclamation of the Salt Lake area on the north eastern fringe of the city, however, has proven that expansion of this city is possible, and further reclamation projects have been undertaken to the east, south and west of the central area. Actually, greater Kolkata extends from Baruipur to Bansberia and Kalyani to Budge Budge. Kolkata enjoys a well linked, speedy and easy approachability from every corner of India. With numerous modes of transport, it is connected through roadways, airways, railways and waterways. The Netaji Shubash Chandra International Airport at Dumdum serves as both domestic as well as international airport in Kolkata. Buses, trams, metro railways, ferries, taxis, auto and cycle rickshaws ply within this city to provide easy and comfortable conveyance to both the locals and visitors. Millions of people thus gather in this city in daily basis to earn their livelihood, and it now becomes almost mandatory for the people to stay nearer to this city for higher comfort and lower transportation cost. For this reason, real estate activities have been intensified in the outskirts as well as in the main parts of this city. Due to the scale of the territory, real estate market presents a wide variety of economic conditions as well as differing supply and demand characteristics. Economic and population growth, higher life quality standards and lower interest rates have led to an increase in the demand for housing. However, in the Kolkata metropolitan area, land for housing is really scarce, and environmental and construction requirements become more stringent. Therefore, an ardent need is realized for an adequate methodology to evaluate the housing projects in and around the city of Kolkata under different perspectives (consumers, developers, municipal authorities etc.) and multiple evaluation (quantitative and qualitative) criteria.

Selection of the best residential property from a plenty of affordable housing projects now becomes an important task to the customers. Low cost housing is usually referred to as affordable housing project by the small developers and builders. It has been identified that there are three main pillars of affordable housing, i.e. speed, quality and value for money (Hui, 2001; Kutty \& New, 2005). Rapid urbanization and growing mid income group are responsible for a huge demand for affordable housing projects. While buying an affordable housing project, builder's reputation is extremely critical, because reputed builders never compromise on the quality and trust factor. Reputation cannot be built overnight, it has to be earned over a period of time. The developer's reputation thus guarantees quality and trust. Provision of basic amenities is also an essential part of the affordable housing projects. Thus, it becomes apparent that identification of the most appropriate residential property in Kolkata amongst several ongoing construction projects while satisfying the customer's requirements and dreams can simply be formulated as a multi-criteria decision making (MCDM) problem. Thus, MCDM refers to the problem of ranking a set of feasible alternatives and identifying the best choice in presence of multiple conflicting attributes/criteria. Several mathematical tools have been successfully deployed to solve varying MCDM problems. It is worthwhile to mention here that most of the existing MCDM methods are based on the concept of expected utility theory, requiring strict assumption about complete rationality of the decision maker. But, in some behavioural experimental studies, it has been inferred that the decision maker has been bounded rational in the decision making process. For example, while selecting an investment project, the decision maker usually has psychological expectations for several attributes, like profit, cost and risk, i.e. reference points. If an attribute value is above the reference point, the decision maker would be satisfied, treating the excess benefit as 'gain'. On the contrary, if an attribute value is below the reference point, the decision maker would be discontented, regarding the deficit part as 'loss'. The decision will be more sensitive to losses than to absolutely commensurate gains. Therefore, solving an MCDM problem considering the decision maker's psychological behaviour becomes a topic of research interest. Although in an MCDM problem, various alternatives can be considered, but from the point of view of a potential investor, the level of information on the possible consequences of each alternative is expected to be known beforehand. The decision making process must meet the important objective according to which, whatever the option chosen, the best must be made of the opportunity, 
without damaging the strategic position of the decision maker and without ignoring other consequent opportunities or taking into account the totality of relevant decision criteria. Thus, it is observed that TODIM (TOmada de Decisao Interativa Multicriterio which means in Portuguese interactive and multi-criteria decision making') method can be an effective MCDM tool to act as a valuable guidance in identifying the most attractive and apposite under-construction housing project in Kolkata while fulfilling the requirements of the investors, inhabitants and other stakeholders. The TODIM method combines both the qualitative and quantitative criteria in order to provide a proper selection decision, and deals with risk while incorporating gain/loss function of prospect theory.

\section{Literature review}

Viteikienė and Zavadskas (2007) applied COPRAS (COmplex PRoportional ASsessment) method for ranking of residential areas according to the indices of sustainable development. Natividade-Jesus et al. (2007) developed a decision support system consisting of a problem editor, a database management module, a set of multi-criteria decision aid methods and a human-computer interface for housing project evaluation. Kahraman and Kaya (2012) applied a fuzzy multi-attribute utility model for assessing three alternative intelligent buildings for a business center in Istanbul. Mulliner et al. (2013) presented the application of COPRAS method in order to measure the affordability of different housing locations while taking into account various economic, environmental and social criteria. Taylan et al. (2014) proposed an integrated application of fuzzy analytic hierarchy process (AHP) and fuzzy technique for order preference by similarity to ideal solution (TOPSIS) for categorization of construction projects. Fuzzy AHP was utilized to determine weights for fuzzy linguistic variables of construction project's overall risk and fuzzy TOPSIS was applied to take the final selection decision. Lazauskas et al. (2015) formulated a multi-criteria model while combining AHP, ARAS (Additive Ratio ASsessment), MOORA (multi-objective optimization on the basis if ratio analysis) and MULTIMOORA (multiplicative MOORA) methods for assessing the unfinished construction projects in Vilnius (capital of Lithuania). From the review of the past researches, it can be propounded that although various MCDM techniques have been deployed for evaluating the affordability of different residential properties/housing projects, the application of TODIM method in this direction, specially in the context of Indian subcontinent, is really scarce. Thus, TODIM method may be of great help in identifying the most attractive and affordable under-construction housing project in the city of Kolkata from various feasible alternatives, keeping in mind the risk involved in this selection process.

\section{TODIM method}

The TODIM is a discrete MCDM method based on the concept of prospect theory (Gomes \& Lima, 1992). The underlying principle of this method is a psychological theory, which was the subject of the Nobel Prize for Economics awarded in 2002. It has been observed that all the existing MCDM methods are practically based on the notion that the decision maker always looks for a solution which corresponds to the maximum of some global measure of value, e.g. the maximum possible value of an utility function in case of multi-attribute utility theory. On the other hand, TODIM method is based on the concept of a global measurement of value calculated while applying the paradigm of prospect theory. This method is thus based on a description, empirically proved, of how people effectively formulate decisions in face of risk. The shape of the value function of this method is same as the gain/loss function of prospect theory. The application of TODIM method is based on a global multi-attribute value function. This function is built in parts, with their mathematical descriptions reproducing the gain/loss function of prospect theory. The global multi-attribute value function then aggregates all the measures of gains and losses over all the criteria. The multi-attribute value function (additive difference function) of TODIM method depends on the projection of differences between the values of any two alternatives to a reference criterion. The TODIM method makes use of paired comparisons between the decision criteria and eliminates occasional inconsistencies arising from these comparisons. Thus, the main idea of TODIM method lies in measuring the dominance degree of each alternative over the remaining ones 
using the prospect value function. Basically, it calculates the partial and overall dominance degrees of each alternative over the other alternatives and finally, leads to a global ranking of the alternatives. It also allows value judgments to be carried out in a verbal scale, using fuzzy value judgments and making use of interdependence relationships among the alternatives. It is also a non-compensatory method where tradeoffs do not occur. Roy and Bouyssou (Gomes \& Rangel, 2009) mentioned TODIM as "a method based on the French School and the American School. It combines aspects of the Multi-attribute Utility Theory, of the AHP method and the ELECTRE methods".

Till date, TODIM method has very limited applications in the field of managerial decision making, like evaluation of residential properties (Gomes \& Rangel, 2009; Moshkovich et al., 2011; Uysal \& Tosun, 2014), selection of the best option for destination of the natural gas reserves (Gomes et al., 2009), evaluation of various types of access to the broadband internet (Rangel et al., 2011), ERP software selection (Kazancoglu \& Burmaoglu, 2013), evaluation of performance levels in green supply chain practices under uncertain environment (Tseng et al., 2014), selection of elective courses for the undergraduate students (Adali et al., 2016) and selection of industrial robots (Sen et al., 2016). In this paper, the applicability and potentiality of TODIM method is explored while selecting the best upcoming residential property in the city of Kolkata. Suppose there is a decision making problem consisting of a set of $n$ alternatives to be evaluated and subsequently ranked based on $m$ quantitative/qualitative criteria, and among those criteria, there is one criterion to be treated as the reference one. For each of the criteria $c$, the contribution of each alternative $i$ to the objective associated with the criterion is then estimated. The TODIM method is also quite suitable for dealing with both quantitative and qualitative criteria. Verbal scales of qualitative criteria are converted to cardinal ones and both types of the data are subsequently normalized. The normalized decision matrix thus contains values between 0 and 1 . The relative measure of dominance of one alternative over another is determined for each pair of alternatives. It is calculated as the sum over all the criteria of both relative gain/loss values for the considered alternatives. The components in this sum may be either gains, losses or zeros, depending on the performance of each alternative with respect to every criterion. After determination of the criteria weights and their normalization, the partial matrices of dominance and the final matrix of dominance are developed. In this stage, a criterion $r$ is to be chosen as the reference criterion for the calculations according to the relative priority assigned to each criterion. Usually, the criterion having the highest weight of importance is identified as the reference criterion. Thus, $w_{c r}$ becomes the weight of criterion $c$ divided by the weight of the reference criterion $r$. Using $w_{c r}$ allows all pairs of differences between the performance measurements to be directed towards the reference criterion. Based on the prospect theory, the dominance of alternative $A_{i}$ over alternative $A_{j}$ is now measured. Finally, the global measures obtained permit the complete rank ordering of all the alternatives.

The procedural steps of TODIM method are presented as below (Gomes and Rangel, 2009; Uysal and Tosun, 2014):

Step 1: As the first step for the implementation of TODIM method, the corresponding decision matrix $X$ needs to be developed. In this matrix, there are $n$ and $m$ numbers of alternatives and evaluation criteria respectively.

$$
X=\left[x_{i c}\right]_{n \times m}=\left[\begin{array}{cccc}
x_{11} & x_{12} & \ldots & x_{1 m} \\
x_{21} & x_{22} & \ldots & x_{2 m} \\
\ldots & \ldots & \ldots & \ldots \\
x_{n 1} & x_{n 2} & \ldots & x_{n m}
\end{array}\right] \quad(i=1,2, \ldots, n ; c=1,2, \ldots, m)
$$

where $x_{i j}$ denotes the performance of $i^{\text {th }}$ alternative with respect to $j^{\text {th }}$ criterion.

Step 2: In order to make this decision matrix dimensionless and all of its elements comparable, it is then normalized. For beneficial criteria requiring higher values, Eq. (2) can be adopted. On the other hand, for non-beneficial criteria preferring with lower values, Eq. (3) can be utilized. 


$$
\begin{aligned}
& P_{i j}=\frac{x_{i c}}{\sum_{i=1}^{n} x_{i c}} \\
& P_{i j}=\frac{1 / x_{i c}}{\sum_{i=1}^{n} 1 / x_{i c}},
\end{aligned}
$$

where $P_{i j}$ is the normalized value of $x_{i j}$.

Step 3: Using AHP or Shannon's entropy method (Lotfi \& Fallahnejad, 2010), the priority weights (relative importance) $\left(w_{j}\right)$ of all the considered criteria are determined. The relative weight $\left(w_{c r}\right)$ of criterion $C_{c}(c=1,2, \ldots, m)$ with respect to the reference criterion $C_{r}$ is then computed using Eq. (4).

$$
w_{c r}=w_{c} / w_{r}
$$

where $w_{r}$ is the weight of the reference criterion. Usually, the reference criterion is selected as that criterion having the maximum weight. The use of $w_{c r}$ allows all pairs of differences between performance measurements to be translated into the same dimension, i.e. that of the reference criterion.

Step 4: Next, the dominance degree of alternative $A_{i}$ over alternative $A_{j}$ is calculated employing the following equation:

$$
\delta\left(A_{i}, A_{j}\right)=\sum_{c=1}^{m} \phi_{c}\left(A_{i}, A_{j}\right) \quad \forall(i, j)
$$

In the above equation, the dominance degree of alternative $A_{i}$ over alternative $A_{j}$, i.e. $\phi_{c}\left(A_{i}, A_{j}\right)$, concerning criterion $C_{c}(c=1,2, \ldots, m)$, is evaluated using Eq. (6).

$$
\phi_{c}\left(A_{i}, A_{j}\right)=\left\{\begin{array}{cc}
\sqrt{\frac{w_{c r}\left(P_{i c}-P_{j c}\right)}{\sum_{c=1}^{m} w_{c r}}} & \text { if }\left(P_{i c}-P_{j c}\right)>0 \\
0 & \text { if }\left(P_{i c}-P_{j c}\right)=0 \\
\frac{-1}{\theta} \sqrt{\frac{\left(\sum_{c=1}^{m} w_{c r}\right)\left(P_{i c}-P_{j c}\right)}{w_{c r}}} & \text { if }\left(P_{i c}-P_{j c}\right)<0
\end{array}\right.
$$

where $P_{i c}$ and $P_{j c}$ are, respectively, the performances of the alternatives $A_{i}$ and $A_{j}$ in relation to $c$, and $\theta$ is the attenuation factor of the losses. The expression $\phi_{c}\left(A_{i}, A_{j}\right)$ denotes the parcel of contribution of criterion $c$ to function $\delta\left(A_{i}, A_{j}\right)$, while comparing $i^{\text {th }}$ alternative with $j^{\text {th }}$ alternative. When $\left(P_{i c}-P_{j c}\right)>0$, it represents a gain for function $\delta\left(A_{i}, A_{j}\right)$; when $\left(P_{i c}-P_{j c}\right)=0$, the value 0 is assigned to $\phi_{c}\left(A_{i}, A_{j}\right)$; and when $\left(P_{i c}-P_{j c}\right)<0$, it denotes a loss of $i^{\text {th }}$ alternative over $j^{\text {th }}$ alternative. The expression for $\phi_{c}\left(A_{i}, A_{j}\right)$ actually permits an adjustment of the data to the value function of prospect theory, thus explaining the aversion and propensity to risk. This function has the shape of an ' $S$ '. Above the horizontal axis, there is a concave curve representing gains, and below the horizontal axis, there is a convex curve symbolizing losses. Different values of $\theta$ may lead to different shapes of the prospect theoretical value function in the negative quadrant.

Step 5: The overall dominance degree of alternative $A_{i}\left(\zeta_{i}\right)$ is determined applying the following expression:

$$
\zeta_{i}=\frac{\sum_{j=1}^{n} \delta\left(A_{i}, A_{j}\right)-\min \sum_{j=1}^{n} \delta\left(A_{i}, A_{j}\right)}{\max \sum_{j=1}^{n} \delta\left(A_{i}, A_{j}\right)-\min \sum_{j=1}^{n} \delta\left(A_{i}, A_{j}\right)} .
$$

Step 6: The alternatives are finally ranked based on the descending values of their dominance scores and the alternative having the maximum dominance score becomes obviously the best choice. 


\section{Under-construction housing project selection in Kolkata}

In order to employ TODIM method for evaluation and selection of the most appropriate and affordable unfinished residential property in the city of Kolkata, 14 alternative housing projects $\left(A_{1}, A_{2}, \ldots, A_{14}\right)$ are considered here which are dispersed over the entire city. At this very moment, all of them are under construction by the city's reputed developers/builders and it is very likely that they will become ready for possession within the next six to eight months. The locations of these under-construction housing projects are shown in Fig.1 with respect to Kolkata's geographical map.

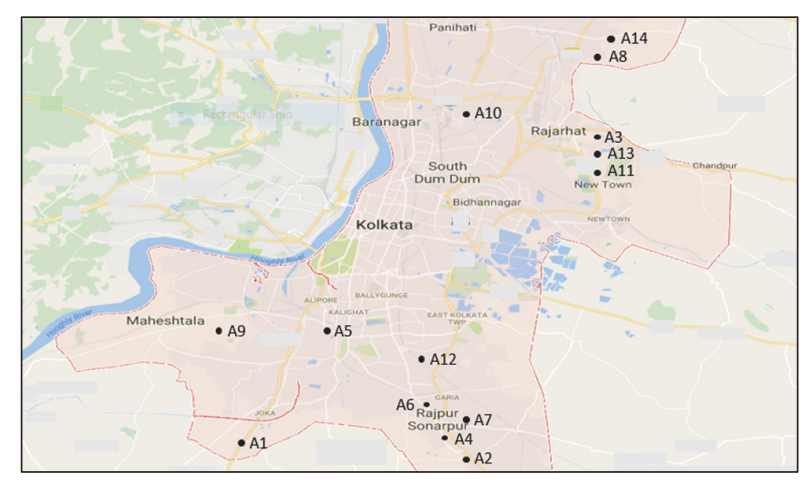

Fig. 1 Locations of 14 under-construction housing projects in Kolkata

These housing projects are now evaluated with respect to ten important criteria which are chosen after taking valuable opinions from the concerned developers/customers/domain experts. Thus, the decision matrix for this under-construction housing project selection problem in Kolkata consists of 14 alternatives and ten evaluation criteria, as shown in Table 1. Thus, it can be propounded that the decision regarding selection of the most apposite housing project on which an investment is to be made, is an extremely complex problem involving risk. In this decision matrix, the first three criteria are related to various cost elements of the considered under-construction housing projects. While evaluating a housing project, its purchase price (cost per sq foot of super build-up area) becomes obviously the most important attribute, followed by its resale price (cost per sq foot of super build-up area after 10 years).

Table 1

Decision matrix for the under-construction housing project selection problem

\begin{tabular}{ccccccccccc}
\hline $\begin{array}{c}\text { Criteria } \\
\text { Alternative }\end{array}$ & $\mathrm{C}_{1}$ & $\mathrm{C}_{2}$ & $\mathrm{C}_{3}$ & $\mathrm{C}_{4}$ & $\mathrm{C}_{5}$ & $\mathrm{C}_{6}$ & $\mathrm{C}_{7}$ & $\mathrm{C}_{8}$ & $\mathrm{C}_{9}$ & $\mathrm{C}_{10}$ \\
\hline $\mathrm{A}_{1}$ & 3250 & 3169 & 9 & 80 & 8.8 & 42 & 2.7 & 3.7 & 7 & 132 \\
$\mathrm{~A}_{2}$ & 3058 & 5405 & 11 & 65 & 8.6 & 25.5 & 6.1 & 12.4 & 8 & 187 \\
$\mathrm{~A}_{3}$ & 3834 & 4047 & 13 & 75 & 1.2 & 20 & 1.8 & 0.9 & 8 & 168 \\
$\mathrm{~A}_{4}$ & 3561 & 4482 & 11 & 55 & 3.7 & 34 & 1.3 & 3.9 & 5 & 197 \\
$\mathrm{~A}_{5}$ & 3953 & 4608 & 18 & 40 & 2.1 & 28 & 1.2 & 2.4 & 6 & 210 \\
$\mathrm{~A}_{6}$ & 5400 & 6173 & 13 & 60 & 1.4 & 32 & 2.4 & 1.7 & 9 & 201 \\
$\mathrm{~A}_{7}$ & 3710 & 4438 & 11 & 58 & 3.5 & 35.4 & 1.1 & 3.7 & 7 & 189 \\
$\mathrm{~A}_{8}$ & 3100 & 3280 & 8.5 & 61 & 11 & 12.8 & 2.0 & 1.6 & 7 & 230 \\
$\mathrm{~A}_{9}$ & 4757 & 4418 & 12 & 48 & 9.4 & 40.7 & 5.7 & 6.7 & 8 & 242 \\
$\mathrm{~A}_{10}$ & 4208 & 5174 & 10.7 & 60 & 7.1 & 18.1 & 1.0 & 3.4 & 8 & 140 \\
$\mathrm{~A}_{11}$ & 3844 & 3500 & 13 & 63 & 6.8 & 18.5 & 9.6 & 3.0 & 6 & 171 \\
$\mathrm{~A}_{12}$ & 3156 & 3205 & 13 & 65 & 4.9 & 38.4 & 6.6 & 5.5 & 7 & 211 \\
$\mathrm{~A}_{13}$ & 4350 & 4522 & 14 & 75 & 3.8 & 19.8 & 3.9 & 2.7 & 9 & 180 \\
$\mathrm{~A}_{14}$ & 3500 & 4112 & 9 & 50 & 13.3 & 14 & 1.5 & 2.1 & 8 & 182 \\
\hline
\end{tabular}

Sometimes, it is observed that due to some unavoidable reasons, the owners of the newly constructed residential apartments cannot stay there and are compelled to let their apartments to others, hoping to be the fulltime residents of their own homes in near future. Rent of these newly developed residential apartments (rent per sq foot per month) can be another crucial criterion in this evaluation process. It is quite evident that this rental price depends on the location of the housing project and facilities available. 
The estimation of these three monetary figures is based on the financial year 2016-17. Any foliage of a plant, either live, freshly cut, or artificial is termed as greenery. They scavenge the carbon dioxide we breathe out, and convert it into oxygen and release to the air for our livelihood. In the present context of pollution free green environment, the tentative customer/owner should always prefer a residential property full of greenery. The next four criteria in this problem, i.e. distance from the nearest Metro station, distance from the airport, distance from the nearest school of national repute and distance from the nearest hospital, are all related to the positional advantages of the considered unfinished housing projects. The Kolkata Metro is a rapid transit system serving Kolkata city and its peripheries. It has nearly more than 300 services daily carrying over 650,000 passengers making it the second busiest metro system in India. There are also several extension programs of Kolkata Metro going on which will ultimately destine to change the life and times for the Kolkata suburbia. Metro Railway in Kolkata thus becomes the main mode of travel for the common people having their workplaces situated in the central, southern and northern parts of Kolkata city. The Netaji Shubash Chandra International Airport at Dumdum serves as both domestic as well as international airport in Kolkata. It provides an excellent connectivity for the people of Kolkata with all the major Indian cities and some international cities too. Schools are treated as the essential requirements of modern time for providing the most suitable, active and formal agency of education. They are developed and grown to fulfil the specific goals, while simultaneously meeting the demands and hopes of the parents with respect to their educational pursuit. Schools are primarily set up to conserve and expand the concepts of culture, tradition and social values. They now become the man-making industries fulfilling the dreams of several aspirant parents. Thus, proper schooling to the children becomes a mandatory and it is preferable to have as many reputed schools as possible in the vicinity of the under-construction housing projects. For any medical emergency, the position of a housing project nearer to public as well as private hospitals cannot also be ignored. It is always preferable that a specific housing project must provide some basic amenities/recreational facilities to its residents/owners, like community center, indoor and outdoor playgrounds, swimming pool, parking, laundry service, high speed internet, basic digital cable, crèche, security, spa, yoga room, library, skywalk etc. Thus, the availability of these basic amenities is a qualitative attribute and is evaluated based on a 10 -point scale $(1=$ minimum facilities and $10=$ maximum facilities $)$. For having a pollution-free environment in the neighbourhood of a residential project, the pollution index (measured on a scale of 250 with respect to pollutant $\mathrm{PM}_{10}$ ) at the site of each under-construction housing project is considered as the last evaluation criterion. The quantitative values of all these evaluation criteria are accumulated from the websites/catalogues of Kolkata's major real estate developers/builders/consultants. The weights (relative importance) of these ten criteria are now determined applying Shannon's entropy method (Lotfi \& Fallahnejad, 2010) so as to avoid involvement of any subjectivity in judgment.

Table 2

Details of the evaluation criteria

\begin{tabular}{clccc}
\hline Sl. No. & Criteria & Type & Symbol & Weight \\
\hline 1. & Cost per sq foot of super build-up area (in Rs.) & Min & $\mathrm{C}_{1}$ & 0.1151 \\
2. & Resale price per sq foot super build-up area after 10 years (in Rs.) & Max & $\mathrm{C}_{2}$ & 0.1139 \\
3. & Rent per month per sq foot (in Rs.) & Max & $\mathrm{C}_{3}$ & 0.1137 \\
4. & Greenery (in \% of the total project area) & Max & $\mathrm{C}_{4}$ & 0.1148 \\
5. & Distance from the nearest Metro station (in km) & Min & $\mathrm{C}_{5}$ & 0.0774 \\
6. & Distance from the airport (in km) & Min & $\mathrm{C}_{6}$ & 0.1027 \\
7. & Distance from the nearest reputed school (in km) & Min & $\mathrm{C}_{7}$ & 0.0616 \\
8. & Distance from the nearest hospital (in km) & Max & $\mathrm{C}_{9}$ & 0.0695 \\
9. & Availability of basic amenities (in relative scale) & Min & $\mathrm{C}_{10}$ & 0.1157 \\
\hline 10. & Pollution index (in terms of PM10) & & & \\
\hline
\end{tabular}

Amongst these criteria, resale price of the project per sq foot of super build-up area, rent of the apartment per sq foot per month, greenery and availability of the basic facilities are beneficial attributes requiring higher values. On the other hand, the remaining six criteria are non-beneficial attributes preferring with their lower values. The details of all these criteria for the most affordable and attractive housing project selection are provided in Table 2. For the application of TODIM method, the decision 
matrix of Table 1 is first normalized while employing Eq. (2) and Eq. (3), depending on the type of the criterion considered (beneficial or non-beneficial). This normalized decision matrix is provided in Table 3. In this problem, it is observed that availability of the basic amenities in a housing project is the most important criterion with a priority weight of 0.1157 . It is hence regarded as the reference criterion and the corresponding $w_{c r}$ values are subsequently estimated. The partial dominance degrees of each alternative housing project $\phi_{c}\left(A_{i}, A_{j}\right)$ over the other alternatives with respect to each considered criterion are then computed while employing Eq. (6). The value of the attenuation factor of losses $(\theta)$ is assumed here as 1 which signifies that the losses will contribute with their real value to the global value. There are 14 matrices of $13 \times 10$ order representing the partial dominance degrees for all the considered housing project alternatives. The partial dominance degrees of the first under-construction housing project alternative $\left(\mathrm{A}_{1}\right)$ over the others considering each criterion are provided in Table 4 . The dominance degree of alternative $A_{i}$ over alternative $A_{j}, \delta\left(A_{i}, A_{j}\right)$ is subsequently calculated using Eq. (5). Finally, the overall dominance degrees for all the candidate alternatives are determined while applying Eq. (7), as shown in Table 5. Now, these under-construction housing projects are ranked in descending order of their overall dominance degrees. From Table 5, it is clearly observed that alternative $\mathrm{A}_{3}$ with the maximum overall dominance degree evolves out as the most attractive and affordable under-construction housing project in Kolkata, followed by alternative $\mathrm{A}_{10}$. On the other hand, alternative $\mathrm{A}_{9}$ is identified as the least preferred housing project to the probable customers. A sensitivity analysis is also carried out while varying the value of $\theta$, the attenuation factor of losses. It is noticed that when its value is altered from 1 to 5 , the positions of the best and the worst under-construction housing projects remain unchanged, although there is a slight variation in the intermediate ranking patterns of the considered alternative projects. Thus, it can be concluded that in spite of the alteration in the value of $\theta$, the preference order of the top-ranked housing projects remains consistent which validates the robustness of TODIM method in solving complex MCDM problems. The under-construction housing project alternative $\mathrm{A}_{3}$, located at Rajarhat in the eastern fringes of Kolkata city, is nested in green. It has several national and international level schools in its neighbourhood, followed by numerous private superspeciality hospitals. It is also close to the Netaji Shubash Chandra International Airport at Dumdum.

Table 3

Normalized decision matrix

\begin{tabular}{|c|c|c|c|c|c|c|c|c|c|c|}
\hline $\begin{array}{c}\text { Criteria } \\
\text { Alternative }\end{array}$ & $\mathrm{C}_{1}$ & $\mathrm{C}_{2}$ & $\mathrm{C}_{3}$ & $\mathrm{C}_{4}$ & $\mathrm{C}_{5}$ & $\mathrm{C}_{6}$ & $\mathrm{C}_{7}$ & $\mathrm{C}_{8}$ & $\mathrm{C}_{9}$ & $\mathrm{C}_{10}$ \\
\hline $\mathrm{A}_{1}$ & 0.0821 & 0.0523 & 0.0541 & 0.0936 & 0.0296 & 0.0395 & 0.0539 & 0.0498 & 0.0680 & 0.0994 \\
\hline $\mathrm{A}_{2}$ & 0.0873 & 0.0893 & 0.0662 & 0.0760 & 0.0303 & 0.0656 & 0.0238 & 0.0149 & 0.0777 & 0.0701 \\
\hline $\mathrm{A}_{3}$ & 0.0691 & 0.0668 & 0.0782 & 0.0877 & 0.2172 & 0.0837 & 0.0809 & 0.2049 & 0.0777 & 0.0781 \\
\hline $\mathrm{A}_{4}$ & 0.0749 & 0.0740 & 0.0662 & 0.0643 & 0.0704 & 0.0492 & 0.1119 & 0.0473 & 0.0485 & 0.0666 \\
\hline $\mathrm{A}_{5}$ & 0.0675 & 0.0761 & 0.1083 & 0.0468 & 0.1241 & 0.0598 & 0.1212 & 0.0768 & 0.0582 & 0.0624 \\
\hline $\mathrm{A}_{6}$ & 0.0494 & 0.1020 & 0.0782 & 0.0702 & 0.1861 & 0.0523 & 0.0606 & 0.1084 & 0.0874 & 0.0652 \\
\hline $\mathrm{A}_{7}$ & 0.0719 & 0.0733 & 0.0662 & 0.0678 & 0.0744 & 0.0473 & 0.1323 & 0.0498 & 0.0680 & 0.0694 \\
\hline $\mathrm{A} 8$ & 0.0861 & 0.0542 & 0.0511 & 0.0713 & 0.0237 & 0.1307 & 0.0727 & 0.1152 & 0.0680 & 0.0570 \\
\hline $\mathrm{A}_{9}$ & 0.0561 & 0.0730 & 0.0722 & 0.0561 & 0.0277 & 0.0411 & 0.0255 & 0.0275 & 0.0777 & 0.0542 \\
\hline $\mathrm{A}_{10}$ & 0.0634 & 0.0855 & 0.0644 & 0.0702 & 0.0367 & 0.0924 & 0.1455 & 0.0542 & 0.0777 & 0.0937 \\
\hline $\mathrm{A}_{11}$ & 0.0694 & 0.0578 & 0.0782 & 0.0737 & 0.0383 & 0.0904 & 0.0151 & 0.0614 & 0.0582 & 0.0767 \\
\hline $\mathrm{A}_{12}$ & 0.0846 & 0.0529 & 0.0782 & 0.0760 & 0.0532 & 0.0436 & 0.0220 & 0.0335 & 0.0680 & 0.0622 \\
\hline $\mathrm{A}_{13}$ & 0.0613 & 0.0747 & 0.0842 & 0.0877 & 0.0686 & 0.0845 & 0.0373 & 0.0683 & 0.0874 & 0.0729 \\
\hline $\mathrm{A}_{14}$ & 0.0762 & 0.0679 & 0.0541 & 0.0585 & 0.0196 & 0.1195 & 0.0970 & 0.0878 & 0.0777 & 0.0721 \\
\hline
\end{tabular}

A connection of Metro Railways between New Garia and the Airport (29.1 km) via E M Bypass, Salt Lake and Rajarhat is likely to start its operation very soon which will provide a greater connectivity of its residents with the other parts of Kolkata. Similarly, the East-West Metro, connecting Salt Lake's Sector V to Howrah in 30 minutes will also be of great help for availing the railway transport using both Sealdah and Howrah stations. It is being developed by one of the renowned real estate builders of Kolkata who has also promised to provide all the basic amenities to the residents/apartment owners. All these positive dimensions are mainly responsible for the housing project alternative $A_{3}$ in taking the top position of the ranking list superseding the other alternatives. A real time view of the unfinished housing project $A_{3}$ is provided in Fig. 2. 
Table 4

Partial dominance degrees of housing project $\mathrm{A}_{1}$ over others with respect to each criterion

\begin{tabular}{ccccccccccccccccccccc}
\hline $\begin{array}{c}\text { Criteria } \\
\text { Alternative }\end{array}$ & $\mathrm{C}_{1}$ & $\mathrm{C}_{2}$ & $\mathrm{C}_{3}$ & $\mathrm{C}_{4}$ & $\mathrm{C}_{5}$ & $\mathrm{C}_{6}$ & $\mathrm{C}_{7}$ & $\mathrm{C}_{8}$ & $\mathrm{C}_{9}$ & $\mathrm{C}_{10}$ & $\delta\left(A_{i}, A_{j}\right)$ \\
\hline $\mathrm{A}_{2}$ & -0.2116 & -0.5694 & -0.3253 & 0.0449 & -0.0943 & -0.5010 & 0.0430 & 0.0493 & -0.2900 & 0.0581 & -1.7963 \\
$\mathrm{~A}_{3}$ & 0.0379 & -0.3568 & -0.4601 & 0.0259 & -1.5566 & -0.6532 & -0.6614 & -1.4935 & -0.2897 & 0.0496 & -5.3579 \\
$\mathrm{~A}_{4}$ & 0.0287 & -0.4364 & -0.3253 & 0.0579 & -0.7262 & -0.3021 & -0.9706 & 0.0133 & 0.0474 & 0.0615 & -2.5518 \\
$\mathrm{~A}_{5}$ & 0.0410 & -0.4568 & -0.6901 & 0.0733 & -1.1048 & -0.4404 & -1.0457 & -0.6232 & 0.0335 & 0.0653 & -4.1479 \\
$\mathrm{~A}_{6}$ & 0.0613 & -0.6600 & -0.4601 & 0.0518 & -1.4220 & -0.3482 & -0.3307 & -0.9184 & -0.4096 & 0.0628 & -4.3731 \\
$\mathrm{~A}_{7}$ & 0.0342 & -0.4290 & -0.3253 & 0.0543 & -0.7611 & -0.2689 & -1.1280 & 0 & 0 & 0.0588 & -2.7650 \\
$\mathrm{~A}_{8}$ & -0.1858 & -0.1269 & 0.0185 & 0.0505 & 0.0214 & -0.9407 & -0.5533 & -0.9700 & 0 & 0.0699 & -2.6164 \\
$\mathrm{~A}_{9}$ & 0.0547 & -0.4256 & -0.3984 & 0.0655 & 0.0121 & -0.1113 & 0.0418 & 0.0394 & -0.2897 & 0.0722 & -0.9393 \\
$\mathrm{~A}_{10}$ & 0.0464 & -0.5392 & -0.2999 & 0.0518 & -0.3026 & -0.7157 & -1.2194 & -0.2515 & -0.2897 & 0.0256 & -3.4942 \\
$\mathrm{~A}_{11}$ & 0.0382 & -0.2191 & -0.4601 & 0.0478 & -0.3354 & -0.7019 & 0.0488 & -0.4090 & 0.0335 & 0.0512 & -1.9060 \\
$\mathrm{~A}_{12}$ & -0.1458 & -0.0723 & -0.4601 & 0.0449 & -0.5518 & -0.1907 & 0.0443 & 0.0337 & 0 & 0.0655 & -1.2323 \\
$\mathrm{~A}_{13}$ & 0.0489 & -0.4430 & -0.5144 & 0.0259 & -0.7095 & -0.6595 & 0.0320 & -0.5153 & -0.4096 & 0.0553 & -3.0892 \\
$\mathrm{~A}_{14}$ & 0.0260 & -0.3698 & 0 & 0.0635 & 0.0278 & -0.8810 & -0.8366 & -0.73917 & -0.2897 & 0.0561 & -2.9429 \\
\hline
\end{tabular}

Table 5

Overall dominance degrees of the housing projects

\begin{tabular}{cccc}
\hline Alternative & $\sum_{j=1}^{n} \delta\left(A_{i}, A_{j}\right)$ & $\zeta_{i}$ & Rank \\
& -37.2109 & 0.3222 & 12 \\
$\mathrm{~A}_{1}$ & -36.2598 & 0.3440 & 11 \\
$\mathrm{~A}_{2}$ & -7.63227 & 1 & 1 \\
$\mathrm{~A}_{3}$ & -31.5227 & 0.4525 & 9 \\
$\mathrm{~A}_{4}$ & -28.7511 & 0.5160 & 7 \\
$\mathrm{~A}_{5}$ & -19.6521 & 0.7245 & 3 \\
$\mathrm{~A}_{6}$ & -25.1163 & 0.5993 & 5 \\
$\mathrm{~A}_{7}$ & -30.2350 & 0.4820 & 8 \\
$\mathrm{~A}_{8}$ & -51.2700 & 0 & 14 \\
$\mathrm{~A}_{9}$ & -19.1202 & 0.7367 & 2 \\
$\mathrm{~A}_{10}$ & -35.0960 & 0.3706 & 10 \\
$\mathrm{~A}_{11}$ & -41.3270 & 0.2278 & 13 \\
$\mathrm{~A}_{12}$ & -21.5136 & 0.6819 & 4 \\
$\mathrm{~A}_{13}$ & -26.7204 & 0.5626 & 6 \\
\hline
\end{tabular}

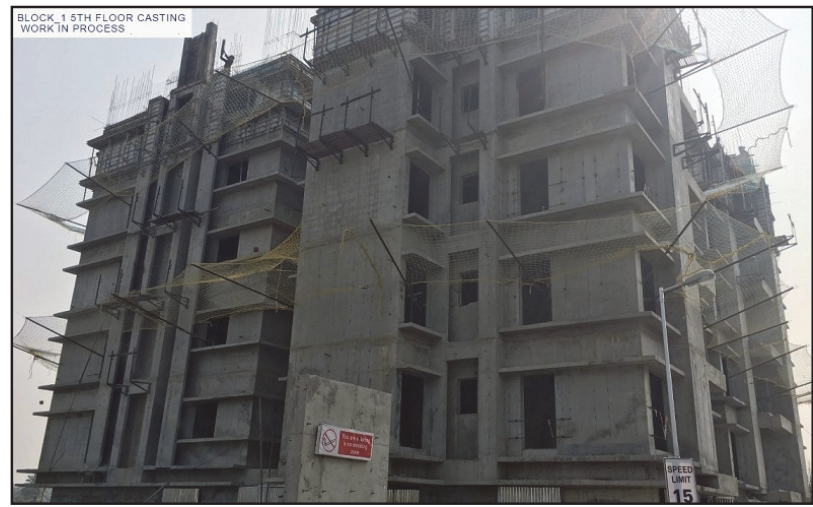

Fig. 2. The top-ranked under-construction housing project

\section{Conclusions}

In this paper, the application of TODIM method is demonstrated to be an extremely helpful MCDM tool in recommending the most attractive and affordable under-construction housing project in the city of Kolkata with respect to a set of qualitative and quantitative criteria with different scales and associated risk factors. The analysis of the under-construction housing projects in Kolkata using TODIM 
method leads to a satisfactory rank ordering, closely in agreement with the expectations of the domain specialists and consultants. It mainly assists the professionals in the real estate market to evaluate different alternatives with respect to criteria defined by the specialists. The application of TODIM method can act as a road map to the tentative customers and other stakeholders in mathematically analyzing and identifying the best residential apartments while fulfilling their dreams under the budgetary constraints. It is also observed that the positions of the best and the worst alternative housing projects remain unaltered with the changing values of the attenuation factor of losses which simultaneously proves the robustness of the adopted method. The application of TODIM method can be extended in evaluating under-construction housing projects in the other metropolitan cities of India too.

\section{References}

Adali, E.A., Işik, A.T., \& Kundakci, N. (2016). Todim method for the selection of the elective courses. European Scientific Journal, August, 314-324.

Gomes, L.F.A.M., \& Lima, M.M.P.P. (1992). TODIM: Basics and application to multicriteria ranking of projects with environmental impacts. Foundations of Computing and Decision Sciences, 16(4), 113-127.

Gomes, L.F.A.M., \& Rangel, L.A.D. (2009). An application of the TODIM method to the multicriteriarental evaluation of residential properties. European Journal of Operational Research, 193(1), 204-211.

Gomes, L.F.A.M., Rangel, L.A.D., \& Maranhão, F.J.C. (2009) Multicriteria analysis of natural gas destination in Brazil: An application of the TODIM method. Mathematical and Computer Modelling, 50(1-2), 92-100.

Hui, E.C.M. (2001). Measuring affordability in public housing from economic principles: Case study of Hong Kong. Journal of Urban Planning and Development, 127(1), 34-49.

Kahraman, C., \& Kaya, T. (2012). A fuzzy multiple attribute utility model for intelligent building assessment. Journal of Civil Engineering and Management, 18(6), 811-820.

Kazancoglu, Y., \& Burmaoglu, S. (2013). ERP software selection with MCDM: Application of TODIM method. International Journal of Business Information Systems, 13(4), 435-452.

Kutty, N.K., \& New, A. (2005). Measure of housing affordability: Estimates and analytical results. Housing Policy Debate, 16(1), 113-142.

Lazauskas, M., Kutut, V., \& Zavadskas, E.K. (2015) Multicriteria assessment of unfinished construction projects. GRADEVINAR, 67(4), 319-328.

Lotfi, F.H., Fallahnejad, R. (2010) Imprecise Shannon's entropy and multi attribute decision making. Entropy, 12, 53-62.

Moshkovich, H.M., Gomes, L.F.A.M., \& Mechitov, A.I. (2011). An integrated multicriteria decision-making approach to real estate evaluation: Case of the TODIM method. Pesquisa Operacional, 31(1), 3-20.

Mulliner, E., Smallbone, \& K., Maliene, V. (2013). An assessment of sustainable housing affordability using a multiple criteria decision making method. Omega, 41(2), 270-279.

Natividade-Jesus, E., Coutinho-Rodrigues, J., \& Antunes, C.H. (2007). A multicriteria decision support system for housing evaluation. Decision Support Systems, 43(3), 779-790.

Rangel, L.A.D., Gomes, L.F.A.M., \& Cardoso, F.P. (2011). An application of the TODIM method to the evaluation of broadband internet plans. Pesquisa Operacional, 31(2), 235-249.

Sen, D.K., Datta, S., \& Mahapatra, S.S. (2016). Application of TODIM (Tomada de Decisión Inerativa Multicritero) for industrial robot selection. Benchmarking: An International Journal, 23(7), 1818-1833.

Taylan, O., Bafail, A.O., Abdulaal, R.M.S., \& Kabli, M.R. (2014). Construction projects selection and risk assessment by fuzzy AHP and fuzzy TOPSIS methodologies. Applied Soft Computing, 17, 105-116.

Tseng, M-L., Lin, Y-H., Tan, K., Chen, R-H., \& Chen, Y-H. (2014). Using TODIM to evaluate green supply chain practices under uncertainty. Applied Mathematical Modelling, 38(11-12), 2983-2995.

Uysal, F., \& Tosun, Ö. (2014). Multi criteria analysis of the residential properties in Antalya using TODIM method. Procedia - Social and Behavioral Sciences, 109, 322-326.

Viteikiene, M., \& Zavadskas, E.K. (2007). Evaluating the sustainability of Vilnius City residential areas. Civil Engineering and Management, 13(2), 149-155.

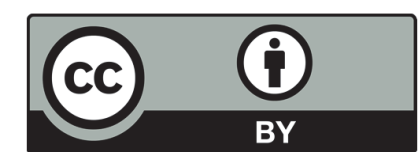

(C) 2018 by the authors; licensee Growing Science, Canada. This is an open access article distributed under the terms and conditions of the Creative Commons Attribution (CC-BY) license (http://creativecommons.org/licenses/by/4.0/). 